\title{
Smooth Wind Power Fluctuation Based on Battery Energy Storage System for Wind Farm
}

\begin{abstract}
Zhang Wei*, Byung Young Moon** and Young Hoon Joo ${ }^{\dagger}$
Abstract - This paper addresses on a wind power system with BESS(Battery Energy Storage System). The concerned system consists of four parts: the wind speed production model, the wind turbine model, configure capacity of the battery energy storage, battery model and control of the BESS. First of all, we produce wind speed by 4-component composite wind speed model. Secondly, the maximum available wind power is determined by analyzing the produced wind speed and the characteristic curve of wind power. Thirdly, we configure capacity of the BESS according to wind speed and characteristic curve of wind speed-power. Then, we propose a control strategy to track the power reference. Finally, some simulations have been demonstrated to visualize the feasibility of the proposed methodology.
\end{abstract}

Keywords: Wind speed, Wind turbine, Wind farm, ESS(Energy Storage System), BESS(Battery energy storage system), Smooth wind power fluctuation

\section{Introduction}

The availability of fossil fuels has had a crucial role in the development of the modern civilization in the last two centuries. However, the raise of primary energy request caused by the demographic growth in developing countries and by an energy starving style of life in developed countries, will lead to an unsustainable situation in the near future, due to the limited fossil fuel reserves still available. Therefore, studies and researches oriented to a broader exploitation of renewable energy sources are powered, as a response to difficulties today experienced in industrialized countries in primary energy procurement[1-2].

Moreover, renewable energy sources represent a quite viable solution to the worrisome increase of air pollution, because of their zero or very low emissions. However, the intermittent nature of wind is the biggest problem associated with wind power. As the installed capacity of wind increases, the problems associated with wind power become magnified. So we need to ensure stability of the wind power system [3, 4].

Energy storage systems are regarded as possible solutions to these problems. Energy storage systems can be used to store electricity at times of high wind and can be discharged in low wind speed, so the electricity is provided when it is needed. Energy storage may also increase the penetration levels attainable by wind energy into generation systems and reduce the amount of alternative generation required as the stored electricity will

$\dagger \quad$ Corresponding Author: Dept. of Control and Robotics Engineering, Kunsan National University, Korea. (yhjoo@kunsan.ac.kr)

* Dept. of Control and Robotics Engineering, Kunsan National University, Korea. (zhw_0704@kunsan.ac.kr)

** Dept. of Naval Architecture and Ocean Engineering, Kunsan National University, Korea. (moonby@kunsan.ac.kr)

Received: July 5, 2014; Accepted: August 20, 2014 be reliable and predictable. Many storage systems are suitable for this application.

There are many researchers researched how to stabilize output power for wind farm. Smoothing wind power fluctuations by controlling the pitch angle was proposed by [16] and [17]. Although this control strategy can smooth the output power of wind farm, the pitch angle cannot fast respond when output power of wind farm need to adjust quickly. Because the pitch angle can be adjusted 7 degrees per second. So the wind farm needs some transition time. Therefore, the output power of wind farm cannot track the power reference quickly. [20] proposed an output power smoothing method by a simple coordinated control of DClink voltage and pitch angle of a wind energy conversion system. Although the output power fluctuations of the wind power in the low and high frequency domains are smoothed by the pitch angle control and the DC-link voltage control, the DC-link voltage will have a large fluctuation. The large fluctuation is not conductive to wind power system stabilization. [18] and [19] proposed the method for smoothing the output power of wind farm by using the energy storage system. Although the proposed ESS can smooth the output power of wind farm when the wind speed is variable, they do not consider tracking the power reference of grid.

This paper addresses the design and the implementation issues on a control strategy for a wind farm, which is made up exclusively of the DFIG(doubly fed induction generators). We mainly contribute to propose a control strategy to smooth output power. The proposed control strategy is as follows: Firstly, we produce the wind speed and obtain the maximum available wind power by analyzing the characteristic curve of the wind power. Next, we configure the capacity of storage system according to wind speed probability distribution and wind speed-power characteristic 
curve of wind turbine. Finally, some simulations have been demonstrated to visualize the feasibility of the proposed methodology.

\section{Preliminary}

\subsection{Wind speed model}

Currently, there are various models to produce the wind speed in the wind power system, such as the Weibull distribution model [5], 4-component composite wind speed model [6], equivalent wind speed model [7] and so on. In this paper, we use the 4-component composite wind speed model to produce the wind speed.

4-component composite wind speed $V_{w t}$ is given by [6]

$$
V_{w t}=V_{w b}+V_{w g}+V_{w c}+V_{w r}
$$

where $V_{w b}$ is the basic wind, $V_{w g}$ is the gust, $V_{w c}$ is the gradual change wind, and $V_{w r}$ is the stochastic wind.

\subsection{Wind turbine model}

A wind turbine is a device that converts kinetic energy from the wind into mechanical one. It consists of four parts: the wind turbine blades, the gearbox, the DFIG, and the converter. Fig. 1 shows configuration of wind turbine.

The wind turbine power conversion $P$ is given by [8]

$$
P=\frac{1}{2} \rho \pi R^{2} V_{w t} C_{p}(\lambda, \beta)
$$

where $\rho$ is the air density, $R$ is the rotor radius, $V_{w t}$ is the wind speed, $C_{p}$ is the power efficiency coefficient, $\lambda$ is the tip speed ratio, and $\beta$ is the blade pitch angle.

\subsection{Energy storage systems}

With the rapid development of electronic technology, there are several types of energy storage system, for example BESS, PHS (pumped hydro-system), FESS (flywheel energy storage system), SMESS (superconducting magnetic energy storage system), CAES (compressed



Fig. 1. Configuration of wind turbine air energy storage) and so on [14].

PHS needs large scale installation with heavy environment impact. CAES and FESS have reduced size respect pumped hydro but not respect batteries. They need complex balance of plant. However, batteries show high efficiency and can be containerized and easy installed in distributed and centralized applications. Also, BESS technology has been very mature. So operating costs and life cycle have been greatly improved. Therefore, we choose BESS to smooth fluctuant wind energy for wind farm.

\subsection{Battery model}

Battery model can usually be divided into experimental model, electrochemical model and equivalent circuit model. Among them, the equivalent circuit model is most suitable for dynamic simulation [15].

The controlled voltage source $E$ for dynamic simulation is given by [9]

$$
E=E_{0}-K \frac{Q}{Q-\int i_{b} d t}+A \exp \left(-B \cdot \int i_{b} d t\right)
$$

where $E$ is no-load voltage $(\mathrm{V}), E_{0}$ is battery constant voltage $(\mathrm{V}), K$ is polarization voltage $(\mathrm{V}), Q$ is battery capacity (Ah), $A$ is exponential zone amplitude $(\mathrm{V})$ and $B$ is exponential zone time constant inverse $\left(\mathrm{Ah}^{-1}\right)$.

\section{Proposed Wind Power System and Control Strategy}

\subsection{Propose wind farm system}

\subsubsection{Wind turbine with BESS}

The intermittent nature of wind is the biggest problem associated with wind power. Therefore, we use BESS to reduce the power fluctuations. Fig. 2 illustrates that the BESS is used to compensate for the intermittent output power of the wind turbine.

As shown in Fig. 2, the DFIG is driven by a wind turbine and a gearbox. The mechanical power output of the

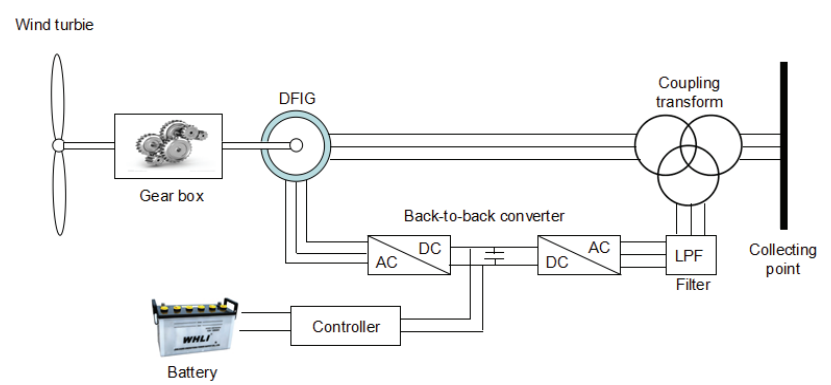

Fig. 2. BESS integration with wind energy conversion system 
wind turbine as a function of wind speed and blade pitch angle is described in the wind turbine model. The BESS is connected into the wind turbine between the DC/AC converter and $\mathrm{AC} / \mathrm{DC}$ converter. Also, the BESS can be charged/discharged to smooth the output power.

\subsubsection{Configure capacity of the BESS}

The configuration of the BESS capacity is very important. If the configuration of the BESS capacity is not enough, the effect of stable output power is not obvious. Conversely, if the configuration of the BESS capacity is very large, the output power is relatively stable but economic costs will increase. So we need to reasonably configure capacity for BESS.

In the previous section, we obtain the wind speed and wind speed-power characteristics curve of wind turbine. Then BESS capacity can be calculated as follows:

We obtain the wind speed and wind speed-power characteristics curve by wind speed model and wind turbine model. Then the expected power of wind turbine of one hour $E$ is calculated as follows:

$$
E=\int v_{\text {cutrin }}^{v_{\text {rated }}} P(v) \cdot q(v) d v+\int v_{\text {ratatout }}^{v_{\text {rated }}} q(v) d v
$$

where $E$ is the expected power of wind turbine of one hour, $P(v)$ is the wind speed-power curve for wind turbine, $q(v)$ is the probability distribution of wind speed, $v_{\text {cut-in }}$ is cut-in wind speed, $v_{\text {rated }}$ is the rated wind speed and $v_{\text {cut-out }}$ is the cut-out wind speed.

The capacity of BESS $S$ is calculated as follows:

$$
S=E^{*} H
$$

Where $H$ is the time of wind turbine keeping the stable output power.

\subsubsection{Wind farm layout}

The wind farm consists of several wind turbines. Its network layout is illustrated in Fig. 3. The wind farm control behaves as a single centralized unit $[10,11]$. It receives input demand from the system operator and measures output from the PCC(point of common coupling). Depending on the actual network status, the system

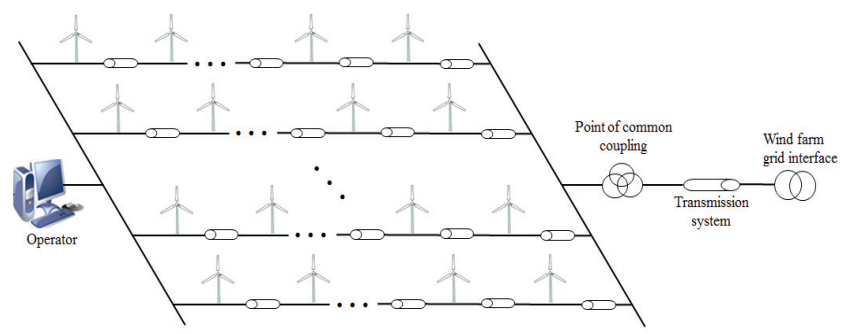

Fig. 3. The network layout of the wind farm

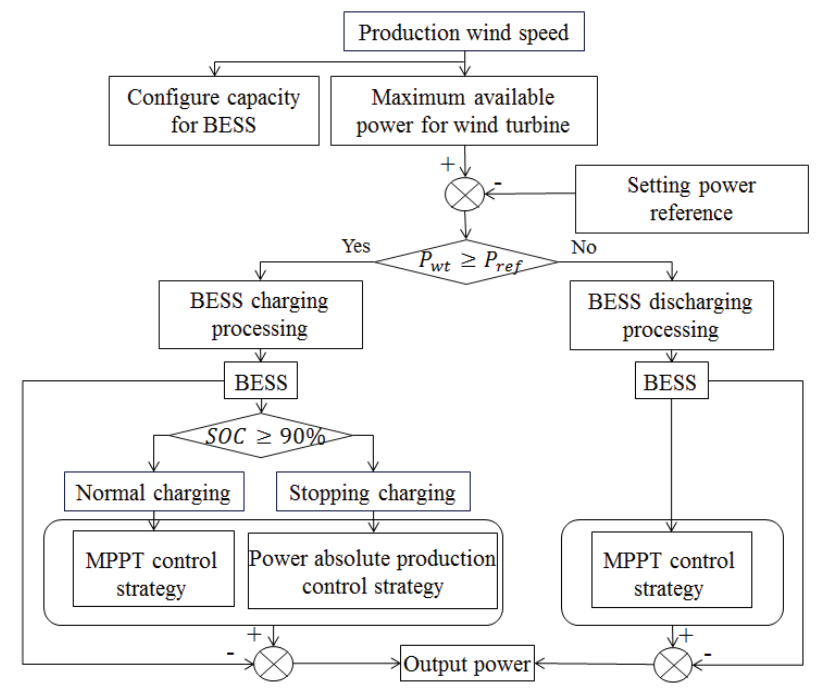

Fig. 4. Control block diagram of wind turbine with BESS

operator requires a certain operation to the wind farm, i.e. operates either with normal production or with absolute production.

\subsection{Proposed control strategy}

The control block diagram of wind turbine with BESS is shown in Fig. 4. As shown in the Fig. 4, the proposed control strategy is divided into two parts. 1) Control for charging/discharging of BESS. 2) Control the wind turbine.

\subsubsection{Control for charging/discharging of BESS}

As mentioned above, the main challenge for wind energy resources is to smooth their intermittent power output. Hence, our problem becomes to develop a method to charge or discharge the BESS in order to smooth their intermittent power output. Also, the state of charging limitations of the BESS should be considered. For this purpose, we use the power difference between the measured power of wind turbine and power reference in order to control charging or discharging of the BESS. The BESS may be divided into a charging phase and a discharging phase as follows:

1) Battery charging phase: This phase is called power peak. The battery stores extra energy when the power reference is smaller than the measured power of wind turbine.

$$
P_{w t}-P_{r e f}=P_{c o m} \geq 0
$$

2) Battery discharging phase: This phase is called power valley. The battery releases energy when the power reference is larger than measured power of wind turbine.

$$
P_{w t}-P_{r e f}=P_{c o m} \leq 0
$$


Where, $P_{w t}$ is the measurement power of wind turbine, $P_{\text {ref }}$ is the power reference of wind turbine and $P_{c o m}$ is the power command of BESS.

\subsubsection{Control of the wind turbine}

For smoothing the output power fluctuation and protecting the BESS, we propose that the wind turbine control is divided into two parts: The first one is that wind turbine is controlled during the battery charging phase. The other one is that wind turbine is controlled during the battery discharging phase. Moreover, SOC (state of charge) of battery has an important impact on the smoothing control of wind power. SOC is defined as the percentage of the capacity $Q$. SOC is calculated as follows:

$$
S O C=\frac{E_{m}-\int_{0}^{t} U_{b} * I_{b}}{E_{b}}
$$

Where, $E_{m}$ is the initial capacity of the battery, $E_{h}$ is the rated capacity of the battery, $U_{h}$ is the voltage of the battery and $I_{h}$ is the current of the battery.

Battery charging phase: The battery storage system stores extra energy. In this phase, we limit SOC to prevent the over-charging of BESS. Therefore, the battery charging phase for SOC is divided into two phase.

1) $S O C \leq S O C_{\max }$ phase: When SOC is smaller than upper limit percentage of the capacity $S O C_{\text {max }}$, we use MPPT control strategy for wind turbines.

2) $S O C \geq S O C_{\max }$ phase: For preventing the overcharging of battery, charging is stopped when the $\mathrm{SOC}$ is larger than $S O C_{\max }$. Therefore, in this phase, we use the power absolute production control strategy to control the wind turbines.

Battery discharging phase: In this phase, we use MPPT control strategy in order to maximize the utilization of wind energy,

MPPT(maximum power point track) and power absolute production control strategy are as follows:

- MPPT

1) Power optimization strategy(below rated wind speed): where the energy capture is maximized by tracking the maximum power coefficient.

2) Power limitation strategy to the rated power value(above rated wind speed): where the power is limited to the rated power of the turbine.

- Power absolute production control strategy

This control strategy will limit the power production to a set maximum power point. Then the measure output power will track the power reference. In here, we use the wind turbine pitch angle to limit the output power. The mathematic model of pitch actuator can be simplified as first-order structure with time delay.

$$
\beta(t)=\frac{e^{-T_{c d} s}}{\tau_{\beta} s+1} \beta_{r e f}(t)
$$

Where, $\tau_{\beta}$ is the time constant of pitch actuator, $T_{c d}$ is the total time delay, including the communication interval and control cycle and $\beta_{r e f}$ is the reference value of pitch angle.

\subsubsection{Control of the wind farm}

The wind farm consists of several wind turbines that BESS are integrated into wind turbines to smooth the output power of wind farm. The power reference of wind farm is distributed to each wind turbine by operator. Then each wind turbine tracks the power reference of each wind turbine by BESS.

\section{Simulation Results}

The effectiveness of BESS is demonstrated through computer simulation by using Matlab/Simulink. The wind farm is connected to the end of transmission line by collecting point. The network layout of the wind farm is illustrated in Fig. 5. Each of the three wind turbines WT1, WT2, WT3 is connected to its own terminal. Both the connection of the wind farm to the station and the station itself are modeled by the actual physical components (transformers, line, busbar). BESS is connected into the back-to-back converter of each wind turbine through the DC bus. Therefore BESS can compensate the output power fluctuation of each wind turbine.

The wind farm is connected to a $25 \mathrm{kV}$ distribution system exports power to a $120 \mathrm{kV}$ grid through a $30 \mathrm{~km}$ $25 \mathrm{kV}$ feeder. Wind turbines use DFIG. The stator winding is connected directly to the PCC and the rotor is driven by a variable-pitch controled wind turbine. The wind farm simulation structure is shown in Fig. 6.

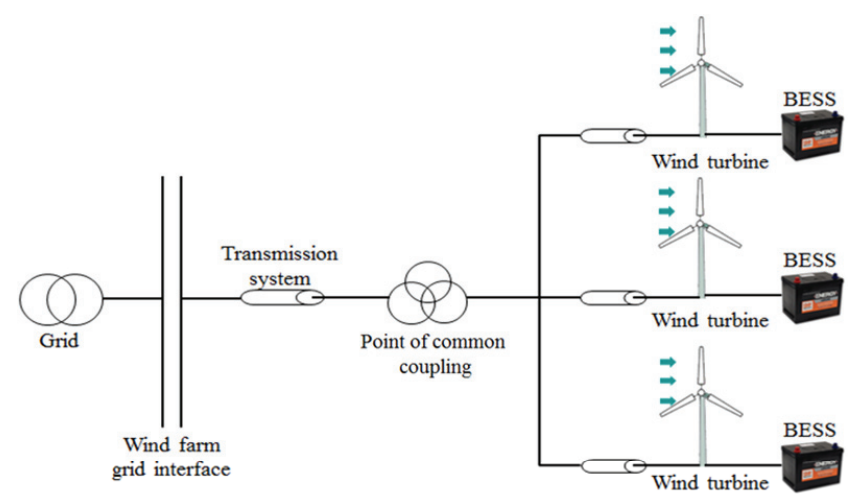

Fig. 5. Wind farm with three wind turbines 


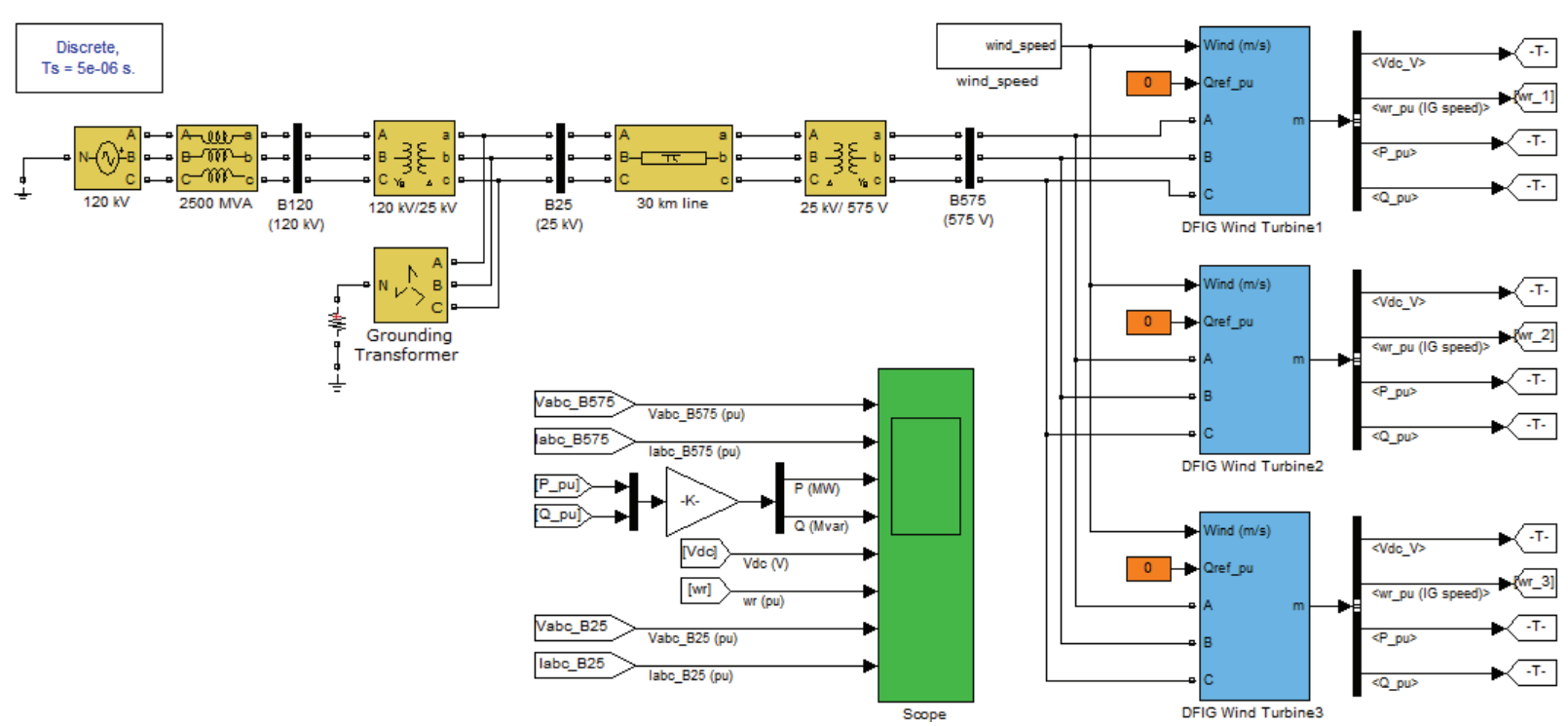

Fig. 6. Wind farm simulation structure

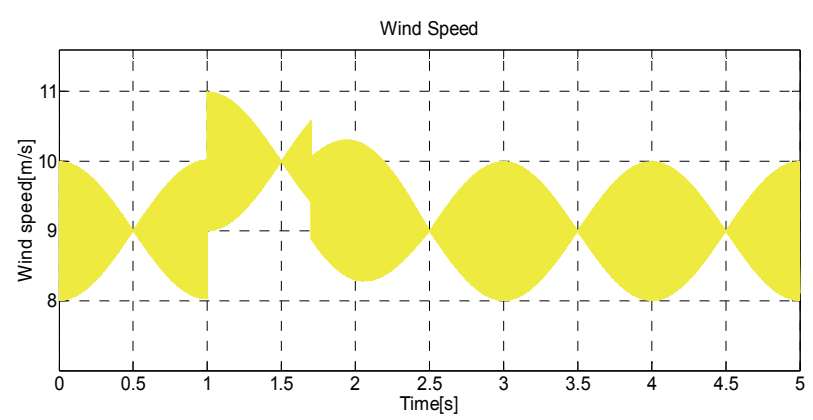

Fig. 7. The 4-component composite wind speed model of the concerned wind farm

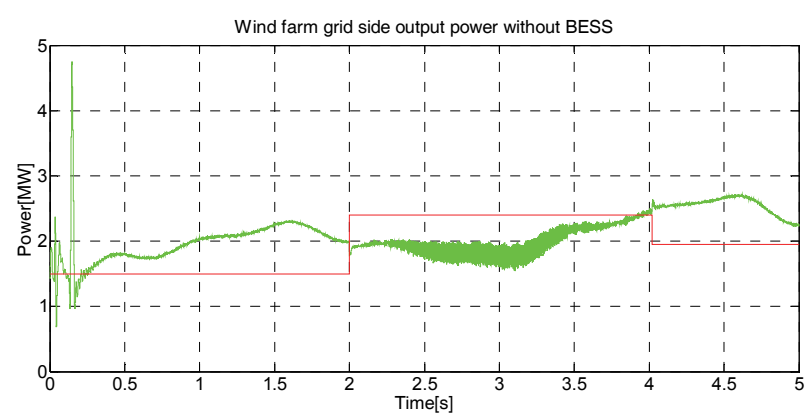

Fig. 8. Output power in wind farm grid side without BESS

The parameters of the performance coefficient of wind turbine are obtained from [12]. And the model of the wind turbine generators is obtained from [13]. The model of the equivalent circuit of BESS is obtained from [9].

The wind speed is produced by 4-component composite wind speed model. In the 4-component composite wind speed model, the basic wind is $9 \mathrm{~m} / \mathrm{s}$, the gust and the gradual change wind are performed from 0 s to $1 \mathrm{~s}$ and from $1 \mathrm{~s}$ to $2.5 \mathrm{~s}$, respectively, the maximum gradient wind is assumed from $1 \mathrm{~s}$ to $1.7 \mathrm{~s}$ and the variable gradient wind is assumed from $1.7 \mathrm{~s}$ to $2.5 \mathrm{~s}$. The stochastic wind is

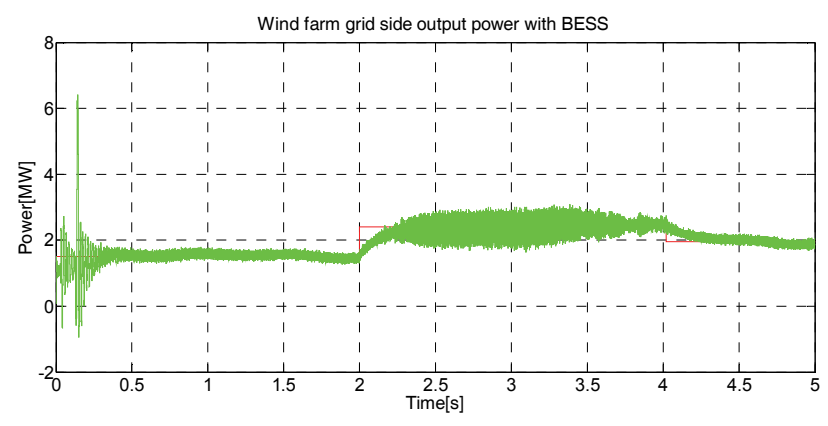

Fig. 9. output power in wind farm grid side with BESS

performed from $0 \mathrm{~s}$ to $5 \mathrm{~s}$. Simulation result of the 4component composite wind speed model of the wind farm is shown in Fig.7.

From Fig. 8, we can find that the output power fluctuation of the wind farm is caused by the variation of wind speed. With the wind farm without BESS, the output power of wind farm exists large fluctuations and the output power of wind farm cannot track the power reference of wind farm. So, the unstable power output will cause a great impact on the grid.

Fig. 9 shows output power of the wind farm with BESS. We can find that the power fluctuation of the wind farm can be rapidly smoothed and the extra power is absorbed or the absent power is compensated by the BESS. When $P_{\text {com }} \geq 0$, the BESS absorbs the extra power. When $P_{\text {com }}<0$, the BESS provides the power to the grid to track the reference power.

Fig. 10 shows the power changing of BESS. Also, taking battery life into account in control, we set $S O C_{\text {max }}=90 \%$ [21]. The BESS stores the extra power when the output power of wind farm is larger than the power reference of wind farm. Conversely, the BESS releases power when the output power of wind farm is smaller than the power reference of wind farm. 


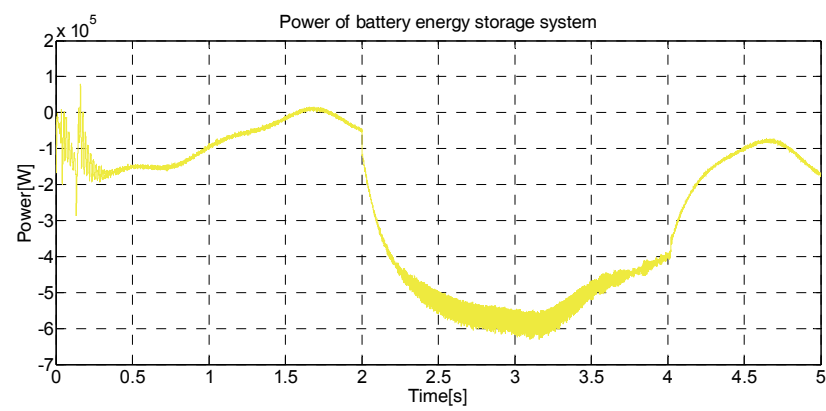

Fig. 10. Power changing of the BESS



Fig. 11. Voltage of DC bus

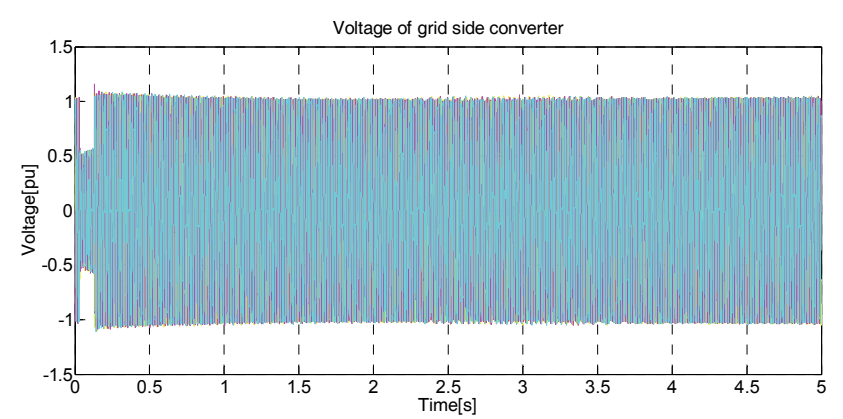

(a) Voltage of grid side converter( $0 \mathrm{~s}-5 \mathrm{~s})$

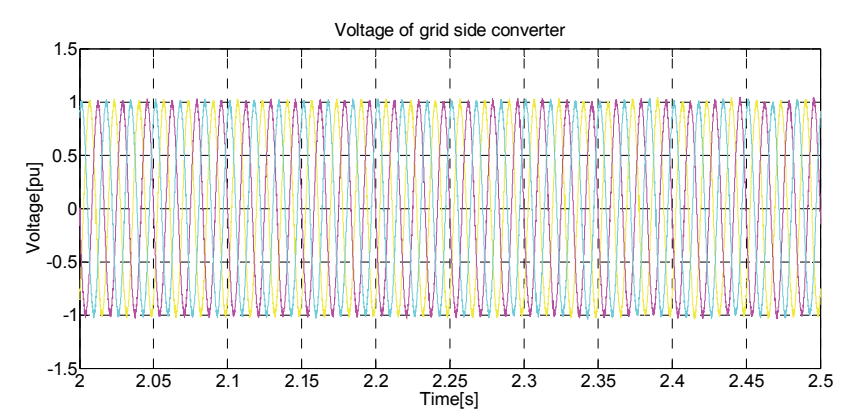

(b) Voltage of grid side converter(2s-2.5s)

Fig. 12. Three-phase voltage of grid side converter

Fig. 11 shows that the DC-link voltage of each wind turbine can be well maintained nearby $1150 \mathrm{~V}$ through the voltage closed loop control of the generator side converter.

Fig. 12 shows the three-phase voltage of each wind turbine. The DC-link voltage is transformed by grid side converter.

\section{Conclusion}

In this paper, we proposed the control strategy for smoothing the wind power fluctuation based on BESS for wind farm. BESS in the DC link of each wind turbine has been investigated with the help of toolbox of MATLAB in order to smooth output power of the concerned wind farm. The proposed control strategy to smooth output power was follows: Firstly, we produced the wind speed and obtained the maximum available wind power by analyzing the characteristic curve of the wind power. Next, we configured the capacity of storage system according to wind speed probability distribution and wind speed-power characteristic curve of wind turbine. Then, we proposed a control strategy to track the power reference. Finally, some simulations have been demonstrated to visualize the feasibility of the proposed methodology. The simulation results show that the proposed control strategy has a strong theoretical forward-looking, it can better control wind power fluctuations and it can maintains the power balance between generation and grid requirement, contributes to the operational security of power system

\section{Acknowledgement}

This work was supported by the Human Resources Development program(No. 20124010203240) of the Korea Institute of Energy Technology Evaluation and Planning (KETEP) grant funded by the Korea government Ministry of Knowledge Economy and by the "Ministry of Energy (MOE) and National Research Foundation of Korea(NRF) through the Human Resource Training Project for Regional Innovation (No. 2013H1B8A2023 237).

\section{References}

[1] G. M. J. Herbert, S. Iniyan, E. Sreevalsan, and S. Rajapandian, "A review of wind energy technologies," Renewable and Sustainable Energy Reviews, vol. 11, no. 6 , pp. 1117-1145, 2007, 8 .

[2] S. A. Sherif, F. Barbir, and T. N. Veziroglu, "Wind energy and the hydrogen economy-review of the technology," Solar Energy, vol. 78, no. 5, pp. $647-$ 660, 2005, 5.

[3] R. Billinton, U. Saskatchewan, Saskatoon, and Yi Gao, "Multistate wind energy conversion system models for adequacy assessment of generating systems incorporating wind energy," Energy Conversion, vol. 23, no. 1, pp. 163-170, 2008, 3.

[4] R. Saidur, M. R. Islam, N. A. Rahim, and K. H. Solangi, "A review on global wind energy policy," Renewable and Sustainable Energy Reviews, vol. 14, no. 7, pp. 1744-1762, 2010, 9. 
[5] Y. Isaac, F. Lun, C. Joseph, and C. Lam. "A study of Weibull parameters using long-term wind observations," Renewable Energy, vol. 20, no. 2, pp. 145-153, 2000, 6 .

[6] H. C. Sung, M. H. Tak, and Y, H, Joo, "Robust fuzzy controller for mitigating the fluctuation of wind power generator in wind farm", Journal of Institute of Control, Robotics and Systems (in Korean), vol. 19, no. 1, pp. 34-39, 2003, 02.

[7] D. Y. Lee, H. C. Sung, and Y, H, Joo, "Fuzzy modeling and robust stability analysis of wind farm based on prediction model for wind speed", Journal of Institute of Control, Robotics and Systems (in Korean), vol. 20, no. 1, pp. 22-28, 2014, 1.

[8] C. Eisenhut, K. Florian, C. Schram, and B. Klockl, "Wind turbine model for system simulations near cutin wind speed," Energy Conversion, vol. 22, no. 2, pp. 414-420, 2007, 6.

[9] O. Tremblay, L. A. Dessaint, and A. I. Dekkiche, “A generic battery model for the dynamic simulation of hybrid electric vehicles," Vehicle Power and Propulsion Conf., pp. 284-289, 2007, 9.

[10] M.Zubiaga, G.Abad, J.A. Barrena, and S. Aurtenetxea, "Evaluation and selection of AC trans-mission layouts for large offshore wind farms," Power Electronics and Applications, pp. 1-10, 2009, 9.

[11] M. R. Aghaebrahimi and V. A. Shandiz, "Using energy storage in grid-connected wind farms for improving economic aspects of wind farm utilization," Electrotechnical Conference, pp. 58-62, 2012, 3.

[12] J. G. Slootweg, H. Polinder, and W. L. Kling, "Representing wind turbine electrical generating systems in fundamental frequency simulations," Energy conversion, vol. 18, no. 4, pp. 515-524, 2003, 12.

[13] L. Shuhui, T. A. Haskew, K. A. Williams and R. P. Swatloski, "Control of DFIG wind turbine with direct-current vector control configuration," Sustainable Energy, vol. 3, no. 1, pp. 1-11, 2012, 1.

[14] H. S. Chen, T. N. Cong, W. Yang, C. Q. Tan, Y. L. Lia and Y. L. Ding, "Progress in electrical energy storage system: A critical review," Progress in Natural Science, vol. 19 , no. 3, pp. 291-312, 2009, 10.

[15] R. C. Kroeze, and R. T. Krein, "Electrical battery model for use in dynamic electric vehicle simulations," Power Electronics Specialists Conference, pp. 1336-1342, 2008, 6.

[16] H. C. Sung, J. B. Park, and Y. H. Joo, "Robust observer-based fuzzy control for variable speed wind power system : LMI approach", Int. Journal of Control, Automation, and Systems, vol. 9, no. 6, pp. 11031110, 2011, 12.

[17] T. Yamazaki, R. Takahashi. T. Murata and J. Tamura, "Smoothing control of wind generator output fluctuations by new pitch controller," Electrical Machines, pp. 1-6, 2008, 9.

[18] L. J. Lin, L. Liang, Y. S. Li and H. Dong, "Study on energy storage system smoothing wind power fluctuations," Power System Technology, 2010 International Conference, pp. 1-4, 2010, 10.

[19] T. Riouch and R.E. Bachtiri, "A coordinated control for smoothing output power of a DFIG based wind turbine," Renewable and Sustainable Energy Conference, pp. 304-309, 2013, 3.

[20] A. Uehara, A. Pratap, T. Goya and T. Senjyu, "A coordinated control method to smooth wind power fluctuations of a PMSG-based WECS," Energy Conversion, vol. 26, no. 2, pp. 550-558, 2011, 6.

[21] D. Ming, X. Ning and B. Rui, "Modeling and comparative study on multiple BESSs," Automation of Electric Power Systems, pp. 34-39, 2011.

[22] H. J. Lee, J. B. Park, and Y. H. Joo, "Robust loadfrequency control for uncertain nonlinear power systems: A fuzzy logic approach", Information Sciences, vol. 176 , pp. $3520-3537,2006.12$

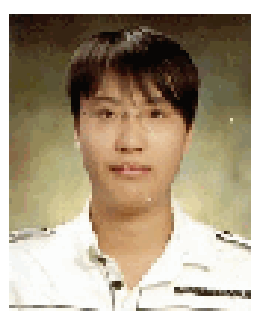

Zhang Wei received his B.S. degree in Department of Control and robot Engineering, Kunsan National University, Korea in 2013. He is currently a MS candidate in Kunsan National University. His research interests are intelligent control and wind farm control.

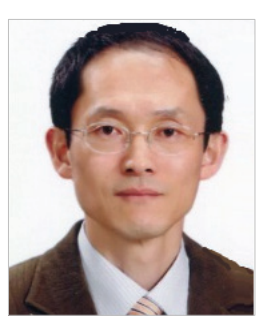

Byung Young Moon received his B.S. degree in ship building engineering from Busan National University, Busan, Korea, in 1992, and received his M.S., and $\mathrm{Ph} . \mathrm{D}$. degrees in mechanical engineering from Kobe University, Japan, in 1996 and 2002, respectively. He worked with Hanjin Heavy Industry Company, Korea, from 1992 to 1996, as a ship designer. He was a Research Fellow in Industrial Bank of Korea from 2006 to 2010, as a shipbuilding engineer. He is currently an assistant professor in the Department of Naval Architecture and Ocean Engineering, Kunsan National University, Korea. His major interest is mainly in the field of design of intelligent ship and offshore structure and sustainable mechanism of system.

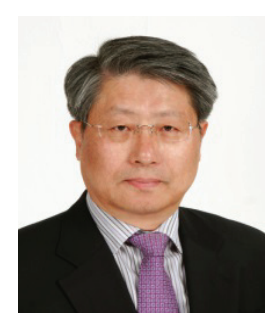

Young Hoon Joo received his B.S., M.S., and Ph.D. degrees in electrical engineering from Yonsei University, Seoul, Korea, in 1982, 1984, and 1995, respectively. He worked with Samsung Electronics Company, Seoul, Korea, from 1986 to 1995, as a project manager. He was with the University 
of Houston, Houston, TX, from 1998 to 1999, as a visiting professor in the Department of Electrical and Computer Engineering. He is currently a professor in the Department of Control and Robot Engineering, Kunsan National University, Korea. His major interest is mainly in the field of intelligent robot, intelligent control, human-robot interaction, robot vision, and wind farm control. He served as President for Korea Institute of Intelligent Systems (KIIS) (2008-2009) and is serving as Editor-in-Chief for the International Journal of Control, Automation, and Systems (IJCAS) (2014-present) and is serving as the VicePresident for the Korean Institute of Electrical Engineers (KIEE) (2013-present). 